\title{
Gastric cancer in India
}

\author{
Keechilat Pavithran ${ }^{1}$, Dinesh C. Doval ${ }^{1}$, and Kamal K. Pandey ${ }^{2}$ \\ ${ }^{1}$ Department of Medical Oncology, Rajiv Gandhi Cancer Institute and Research Centre, New Delhi-110085, India \\ ${ }^{2}$ Department of Surgical Oncology, Rajiv Gandhi Cancer Institute and Research Centre, New Delhi, India
}

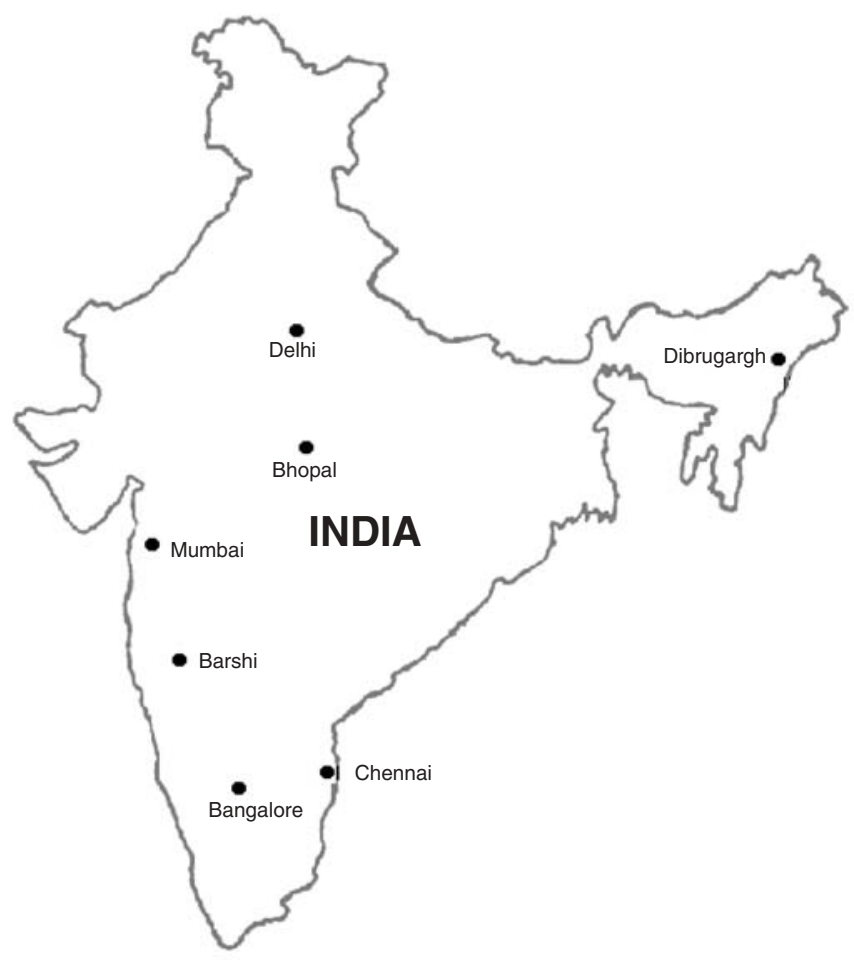

\section{Introduction}

Gastric cancer has a wide geographic variation. Countries in Asia with a high incidence include Japan, China, and South Korea; those with a low incidence include India, Pakistan, and Thailand. Until recently gastric cancer was the second most common cancer worldwide. Now it has moved to the third place, behind breast cancer. It is the second most common cause of death from cancer (734000 deaths annually) [1]. Two-thirds of the cases occur in developing countries. Incidence rates in men are twice those in women, in both low-risk and high-risk areas.

Offprint requests to: K. Pavithran

Received: July 8, 2002 / Accepted: September 30, 2002

\section{Burden of cancer in India}

As per the 2001 census, the population of India is 1027015247. The burden of new cancer cases has been estimated based on data from five population-based cancer registries (Bangalore, Barshi, Bhopal, Chennai, and Delhi) in the network of the National Cancer Registry Programme in India. The estimated number of new cancer cases in 1995 was 311460 in men and 340683 in women [2]. Lung cancer is the most common cancer among males, with cervical cancer the most common in females. Crude incidence rates (CRs) and age-adjusted incidence rates (AARs) per 100000 (1990-1996) for all sites are shown in Table 1. The CR was lowest in Barshi and highest in Chennai for both males and females. The AAR was highest in Delhi for both males and females [3]. The crude mortality rate was highest in Chennai, whereas the age-adjusted mortality rate was highest in Mumbai for both males and females (Table 2) [3]. Tobacco-related cancers constitute $32.7 \%$ of total cancers seen in India.

The number of new digestive tract cancer cases in 2001 was estimated to be approximately 145000 in India. In men and women, the esophagus (24925 in men and 18608 in women) is the commonest site, followed by the stomach ( $n=23785$ in men; 11890 in women) [4]. The AAR of gastric cancer in urban registries (3.013.2) is on the lower side among those reported worldwide (4.1-95.5). It is a disease mainly of males. Gastric cancer occurs a decade earlier among South Indians compared with the North Indians [5].

\section{Regional variation}

In India, across the various registries, there is a wide variation in the incidence of gastric carcinoma. The incidence rate of gastric cancer is four times higher in Southern India compared with Northern India [5]. 
Table 1. Crude and age-adjusted incidence rates of cancer in India (1990-1996)

\begin{tabular}{lrrrrr}
\hline & \multicolumn{2}{c}{ Male } & & \multicolumn{2}{c}{ Female } \\
\cline { 2 - 3 } \cline { 5 - 6 } Registry & CR & AAR & & CR & AAR \\
\hline Bangalore & 62.4 & 97.8 & & 79.9 & 122.1 \\
Barshi & 38.1 & 46.2 & & 48.5 & 57.7 \\
Bhopal & 56.9 & 100.4 & & 55.6 & 92.2 \\
Chennai & 78.6 & 104.6 & & 91.4 & 115.3 \\
Delhi & 73.8 & 121.9 & & 87.3 & 135.3 \\
Mumbai & 72.9 & 115.4 & 82.1 & 119.1 \\
\hline
\end{tabular}

$\mathrm{CR}$, Crude incidence rate; $\mathrm{AAR}$, age-adjusted incidence rate

Table 2. Crude and age-adjusted mortality rates of cancer in India (1990-1996)

\begin{tabular}{lccccc}
\hline & \multicolumn{2}{c}{ Male } & & \multicolumn{2}{c}{ Female } \\
\cline { 2 - 3 } \cline { 5 - 6 } Registry & CMR & AAMR & & CMR & AAMR \\
\hline Bangalore & 19.0 & 30.3 & & 19.1 & 29.4 \\
Barshi & 31.8 & 38.4 & & 33.0 & 39.7 \\
Bhopal & 19.8 & 34.8 & & 15.3 & 27.3 \\
Chennai & 46.3 & 62.1 & & 43.0 & 55.7 \\
Delhi & 20.2 & 34.3 & & 17.2 & 28.9 \\
Mumbai & 36.9 & 62.2 & & 36.6 & 58.2 \\
\hline
\end{tabular}

CMR, Crude mortality rate; AAMR, age-adjusted mortality rate

Table 3. Age-adjusted incidence rates of gastric cancer (1990_ 1996)

\begin{tabular}{lrrrrr}
\hline & \multicolumn{2}{c}{ Males } & & \multicolumn{2}{c}{ Females } \\
\cline { 2 - 3 } \cline { 5 - 6 } & Rank & AAR & & Rank & AAR \\
\hline Chennai & 1 & 13.6 & & 3 & 6.5 \\
Bangalore & 1 & 9.5 & & 6 & 5.1 \\
Mumbai & 5 & 6.4 & & 7 & 3.2 \\
Delhi & 10 & 3.9 & & 12 & 2.5 \\
Bhopal & 9 & 3.4 & & 9 & 1.8 \\
Barshi & 15 & 1.2 & & 6 & 0.8 \\
\hline
\end{tabular}

Among the six registries, the highest incidence in both sexes is reported from Chennai and the lowest from Barshi (Table 3). The incidence varies among different religious groups also. In Kashmir, Muslims have a higher incidence compared with Hindus, whereas the reverse trend is seen in Mumbai.

\section{Tumor sites within the stomach}

Worldwide, the incidence of proximal gastric carcinoma is on the increase. In India also a trend towards an increase in the incidence of cardia tumors is seen. This is evident in the data from Mumbai, where the percentage of cardia and fundus tumors increased from $13 \%$ in
$1941-1968$ to $23 \%$ in $1987-1993$ [6]. Nearly $95 \%$ of the tumors are adenocarcinomas. These may be further distinguished as intestinal and diffuse types. Intestinal type is seen more commonly than diffuse type in India. Early gastric cancer is defined as tumor limited to the mucosa and submucosa irrespective of lymph node involvement. In India more than $90 \%$ of all gastric cancers are diagnosed in an advanced stage, and in those subjected to surgery more than $70 \%$ have serosal infiltration [6].

\section{Risk factors}

The etiology of gastric cancer is multifactorial. The intestinal type of gastric carcinoma develops in a multistep pathway. In a case-control study from Chennai, smokers had a twofold increased risk of gastric cancer compared with nonsmokers, and the risk seen among current smokers was significantly higher than that seen among ex-smokers. The risk among those who smoke "bidi" (a type of local cigarette made from suncured tobacco that is rolled in a rectangular piece of dried leaf of Diospyros melanoxylon) was thrice than that seen among cigarette smokers. The habits of drinking alcohol and chewing "quid" (leaf of Piper betel containing small pieces of areca nut and a pinch of aqueous lime) did not emerge as risk factors in this study [7]. However, Rao et al. [8] did not find any relation between tobacco use and risk of gastric cancer. In another study, a high consumption of rice with chilli, and the consumption of high-temperature foods were (sevenfold increased risk) found to be independent risk factors. However, the consumption of vegetables and fruits was found to reduce the risk [9]. In a case-control study from Mumbai, the consumption of dry fish once every 2 weeks was found to increase risk 12-fold [8]. Salted tea, prepared by brewing green tea leaves with sodium bicarbonate, is the favorite drink among Muslims in Kashmir. It shows high methylating activity upon in-vitro nitrosation. In addition, other dietary items containing substantial amounts of N-nitroso compounds, such as sun-dried vegetables, dried fish, and red chillies, are substantially consumed by this population [10]. Helicobacter pylori has been accepted as being carcinogenic in humans. H. pylori causes carcinogenesis by inducing chronic atrophic gastritis. There is a strong link between $H$. pylori infection and gastric cancer in many countries, such as Japan. Even though the prevalence of $H$. pylori infection is high $(49.4 \%$ to $83.3 \%$ ) in India [11,12], gastric cancer rates are low. The role of $H$. pylori in gastric cancer has been reported in three studies from India. Of these, only one study showed a positive association [13]. Smokers with Cag A-positive $H$. pylori infection have a strongly increased 


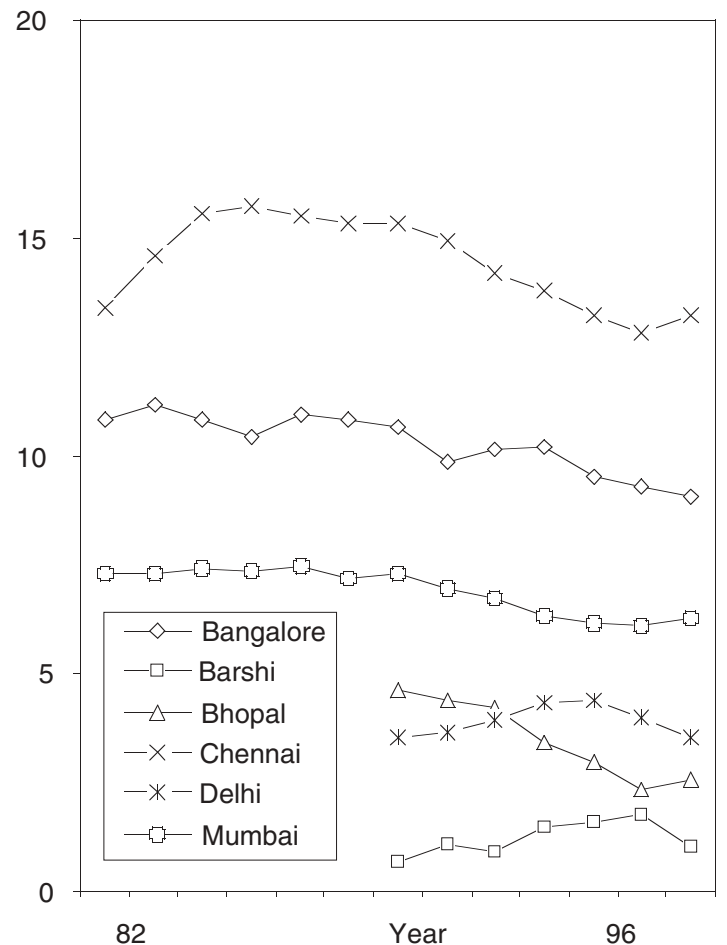

Fig. 1. Time trends in age-adjusted incidence rates of gastric cancer in India over the years 1982-1996 (reproduced with kind permission from the National Cancer Registry Programme (ICMR), Coordinating Unit, Bangalore)

risk of gastric cancer, and this is particularly important in developing countries where both factors are widely prevalent [14]. H. pylori may act as a cofactor in the pathogenesis of gastric carcinoma, along with other risk factors.

Cancer of the esophagus is seen more commonly than gastric cancer in India. This has been attributed to both dietary and nondietary factors. Dietary factors that have been reported as risk factors are high temperature of food; the consumption very strong chillies, pickles, and spices; and the consumption of leftover food $[15,16]$ and Kalakhar [16]. Kalakhar, which is used by the indigenous population of Assam and other North-Eastern states, is a highly alkaline ( $\mathrm{pH} 11-12$ ) substance made from the skin of a particular variety of banana. It is used as an additive during the preparation of curry or "dhal". Consumption of Kalakhar was associated with an eightfold increased risk. Nondietary factors that were noted to have a significant association with esophageal cancer were betel nut and tobacco chewing and "bidi" smoking $[17,18]$.

\section{Time trends}

In most developed countries there has been a persistent and progressive decline in both the incidence and the mortality of gastric cancer in the past 50 years. This is principally because of changes in diet and in the preparation and preservation of food (increased use of refrigeration). This trend is seen among most registries in India also (Fig. 1) [3]. In Chennai there was a slight increase in the early 1980s, but this flattened out and has shown a decline since then. However, this has not been found to be statistically significant. A declining trend is seen in Mumbai and Bangalore also.

\section{Treatment and survival}

Surgery is the main modality of treatment practiced in this country. However, extensive lymph node dissection, as practiced in Japan and other countries, is not followed here regularly. Curative surgery is done in about $20 \%$ of the cases and palliative surgery in one-third of the cases. The prognosis of gastric cancer remains relatively unchanged despite major improvements in diagnosis and therapy. Reports from different parts of the country show 5-year overall survival rates ranging from $5 \%$ to $18 \%[19,20]$. This is similar to the reports from Western countries also.

\section{Conclusion}

The incidence of digestive cancers, except for gallbladder cancer, is low in India. The rates in rural populations are much lower than those in the urban populations. Gastric cancer is showing a declining trend in India. The low incidence rates, limited resources, and inadequate public health services do not permit routine screening procedures in India. Reducing tobacco usage and improving dietary habits and public health education would be a more affordable approach to reduce the occurrence of these cancers.

Acknowledgments The authors thank Dr. A. Nandakumar, Project Officer, National Cancer Registry Programme (ICMR), Coordinating Unit, Bangalore, India, for critical review of the manuscript.

\section{References}

1. Parkin DM, Bray FI, Devesa SS. Cancer burden in the year 2000. The global picture. Eur J Cancer 2001;37:S4-S66.

2. Gajalakshmi V, Santha V, Swaminathan R. History of population based cancer registries in India. Asian Pacific J Cancer Prev 2001;2:13-20. 
3. Consolidated report of the population based cancer registries 1990-96. National Cancer Registry Programme. New Delhi: Indian Council of Medical research; 2001.

4. Mohandas KM, Jagannath P. Epidemiology of digestive tract cancers in India. VI. Projected burden in the new millennium and the need for primary prevention. Indian J Gastroenterol 2000; 19:73-8.

5. Malhotra SL. Geographical distribution of gastrointestinal cancers in India with special reference to causation. Gut 1967;8: 361-72.

6. Mohandas KM, Nagral A. Epidemiology of digestive tract cancers in India. II. Stomach, and gastrointestinal lymphomas. Indian J Gastroenterol 1998;17:24-7.

7. Gajalakshmi CK, Shanta V. Lifestyle and risk of stomach cancer: a hospital-based case-control study. Int J Epidemiol 1996;25: 1146-53.

8. Rao DN, Ganesh B, Dinshaw KA, Mohandas KM. A case-control study of stomach cancer in Mumbai, India. Int J Cancer 2002;99: 727-31.

9. Mathew A, Gangadharan P, Varghese C, Nair MK. Diet and stomach cancer: a case-control study in South India. Eur J Cancer Prev 2000;9:89-97.

10. Siddiqi M, Kumar R, Fazili Z, Spiegelhalder B, Preussmann R. Increased exposure to dietary amines and nitrate in a population at high risk of oesophageal and gastric cancer in Kashmir (India). Carcinogenesis 1992;13:1331-5.

11. Alaganantham TP, Pai M, Vaidehi T, Thomas J. Seroepidemiology of Helicobacter pylori infection in an urban, upper class population in Chennai. Indian J Gastroenterol 1999;18:66-8.
12. Prasad S, Mathan M, Chandy G, Rajan DP, Venkateswaran S, Ramakrishna BS, et al. Prevalence of Helicobacter pylori in southern Indian controls and patients with gastroduodenal disease. J Gastroenterol Hepatol 1994;9:501-6.

13. Sivaprakash R, Rao UA, Thyagarajan SP, Ramathilakam B, Jayanthi $\mathrm{V}$. Investigation for the prevalence of Helicobacter pylori infection in patients with gastric carcinoma in Madras, India. Jpn J Med Sci Biol 1996;49:49-56.

14. Brenner H, Arndt V, Bode G, Stegmaier C, Ziegler H, Stumer T. Risk of gastric cancer among smokers infected with Helicobacter pylori. Int J Cancer 2002;98:446-9.

15. Phukan RK, Chetia CK, Ali MS, Mahanta J. Role of dietary habits in the development of esophageal cancer in Assam, the north-eastern region of India. Nutr Cancer 2001;39:2049.

16. Khuroo MS, Zargar SA, Mahajan R, Banday MA. High incidence of oesophageal and gastric cancer in Kashmir in a population with special personal and dietary habits. Gut 1992;33:11-5.

17. Phukan RK, Ali MS, Chetia CK, Mahanta J. Betel nut and tobacco chewing; potential risk factors of cancer of oesophagus in Assam, India. Br J Cancer 2001;85:661-7.

18. Sankaranarayanan R, Duffy SW, Padmakumary G, Nair SM, Day NE, Padmanabhan TK. Risk factors for cancer of the oesophagus in Kerala, India. Int J Cancer 1991;49:485-9.

19. Sarker SK, Sinha VK, Chaudhry R, Maudar KK. Gastric cancer: a critical analysis of surgical treatment and long term survival. J Indian Med Assoc 1992;90:61-4.

20. Prakash A, Pandit PN, Poddar PK, Sharma LK. Carcinoma of the stomach. Int Surg 1975;60:270-2. 